\title{
A Web-Based Irrigation Scheduling Model to Improve Water Use Efficiency and Reduce Nutrient Leaching for Florida Citrus ${ }^{1}$
}

\author{
Kelly T. Morgan, Edward A. Hanlon, and Thomas A. Obreza ${ }^{2}$
}

\section{Introduction}

The competition for water supply is increasing throughout Florida. Increasing demands from residential and commercial users are often met at the expense of agricultural and environmental water supplies. One way that citrus producers can address this trend is by improving their water use efficiency. Irrigation managers can reduce grove water consumption while avoiding tree damage or fruit yield/quality loss due to insufficient irrigation. The key to improving water management is to include soil characteristics and weather factors in irrigation scheduling decisions. An easy to use web-based water-balance irrigation scheduling tool has been developed. This tool will assist growers in determining irrigation schedules that can improve water use efficiency and reduce nutrient leaching. The tool can be found at: http://fawn.ifas.ufl.edu/tools/irrigation/citrus/ scheduler/.

Grove managers may have several objectives for irrigating. Increased profit through the effective use of irrigation to produce high quality citrus is the overall goal. Irrigation scheduling in combination with fertilizer best management practices (BMPs) will provide maximum nutrient uptake efficiency, which is defined as the amount of fertilizer taken up by the tree divided by the amount applied. This objective attempts to hold nutrients, especially the mobile nutrients such as nitrate-nitrogen, in the root zone via measured irrigation events. Irrigation timing and duration are based upon crop need and soil-moisture content. In addition to addressing plant water needs, moisture changes in the soil volume containing the root zone are included, as well as irrigation delays for rainfall events.

\section{Factors Affecting Irrigation Scheduling}

Citrus soils vary from the deep, well-drained soils of the Florida central ridge to the poorly-drained, coastal flatwoods soils. The surface layers of both types of soil are similar (greater than $95 \%$ sand and less that $2 \%$ organic matter). However, the soil layers below 24 inches vary greatly. Ridge

1. This document is SL286, one of a series of the Soil and Water Science Department, Florida Cooperative Extension Service, Institute of Food and Agricultural Sciences, University of Florida. Original publication date May 2009. Visit the EDIS Web Site at http://edis.ifas.ufl.edu.

2. Kelly T. Morgan, assistant professor; Edward A. Hanlon, professor, Soil and Water Science Department, Southwest Florida Research and Education Center--Immokalee; Thomas A. Obreza, professor, Soil and Water Science Department; Florida Cooperative Extension Service, Institute of Food and Agricultural Sciences, University of Florida, Gainesville, FL 32611. 
soils can have very little change in soil characteristics to several feet deep and are considered excessively well drained and other ridge soils may have broken or complete clay layers a few feet below the surface that make them less well drained. Flatwoods soils typically have a clay and/or organic layer at less than 3 to 5 feet that makes them poorly drained.

Management techniques for irrigating commercial citrus groves must take differences in soils and related water regimes into consideration. The water holding capacity and physical characteristics of these soil types greatly influence root distribution, the presence of a water table, and the need for drainage. Irrigation practices must address these characteristics to effectively irrigate the trees without leaching nutrients below the root zone and into surface or ground water.

Ridge soils allow citrus roots to penetrate deep into the soil. This root distribution pattern anchors the tree and provides a large volume of soil, typically 36 inches or deeper, from which the tree may extract both nutrients and water. Flatwoods soils are almost always poorly drained, and they flood relatively easily. Drainage and the presence of an impermeable soil layer have considerable influence on citrus root distribution in these soils. The shallow root system is restricted to the upper 12 to 18 inches of soil.

Irrigation duration and flow rate determine the volume of water that is added to the grove. Irrigation water applied in excess of the soil water holding capacity either continues through the soil profile below the root zone, and/or reaches the water table. In both cases, water applied above the amount required to refill the soil in the root zone is wasted and may potentially contribute to water contamination. This simplified model of water movement has been called "piston flow" because water entering the soil from irrigation or rainfall forces existing water in the soil to move deeper into the soil profile. This process also describes the flow of mobile nutrients in the sandy soils of central and south Florida, making them vulnerable to nutrient leaching. Irrigation must be scheduled to avoid or minimize loss of nutrients, especially nitrogen, from the citrus root zone.
A good way to know if irrigation water is being used correctly (avoiding too wet or too dry conditions) is to estimate the depth of wetting and the total depth of soil that will be filled to field capacity. A simple irrigation schedule can be estimated using available information and making some assumptions. The addition of one inch of water will wet a Candler soil to field capacity to a depth of approximately 50 inches, given an original soil-water content of $1 / 3$ depletion (the recommended soil moisture content for irrigation in the spring). Using the same assumptions, a flatwoods soil (e.g., Wabasso) would be wet to field capacity to a depth of about 25 inches by the same one inch of water at the same $1 / 3$ depletion. Of course, a wetter soil at the beginning of the irrigation cycle would result in soil being brought to field capacity to a greater depth. Based upon tree rooting depths, the implication is that a water application in excess of one inch may extend field capacity conditions below the rooting depth of the citrus trees grown in both Candler and Wabasso soils.

Water budgeting and use of soil moisture sensors are two methods of irrigation scheduling that will improve the likelihood of obtaining the irrigation goals stated above. The reminder of this article will address the use of a water budget for irrigation scheduling.

\section{Water Budget Approach}

When water is lost from the soil by evaporation and the citrus tree loses water through transpiration, water must be supplied to replace evapotranspiration (ET). A reference evapotranspiration (ETo) can be used as a basis for estimating citrus grove ET (ETc) or irrigation demand. Reference ET is calculated on a daily basis using weather data (e.g. maximum temperature, minimum temperature, relative humidity solar radiation and wind), which are available from the nearest FAWN site at http://fawn.ifas.ufl.edu.

Two factors ( $\mathrm{Kc}$ and $\mathrm{Ks}$ ) must be used to convert the ETo (calculated based on a grass crop) to one that reflects citrus growing in specific soils and conditions observed in the grove of interest. The equation: ETc $=\mathrm{ETo} * \mathrm{Kc} * \mathrm{Ks}$ uses these components to estimate the ETc. The crop coefficient $(\mathrm{Kc})$ determines the relative amount of water used by a crop based on 
growth patterns and changes throughout the year. It is low during the cooler months when water use is low and higher in the warm summer months when water use by the citrus trees is high. The soil-water extraction factor $(\mathrm{Ks})$ is an estimate of the trees' ability to remove water throughout a range of water contents. As soils dry out, the Ks is reduced. Tree roots must expend more and more energy to take up water from the soil, thus the trees remove less water, and the Ks gets smaller. When soil water is depleted by as little as $50 \%$, tree water uptake can be reduced by as much as $40 \%$. Reduced water uptake by the tree can result in reduced tree growth and yield. Thus, growers are advised to keep their soil above the recommended maximum allowable soil water depletion for the given time of the year so that Ks remains as high as possible. The UF/IFAS recommendation is to allow 25 to $33 \%$ soil-water depletion during February through May, and 50 to $66 \%$ depletion during June through January. These allowable depletions provide more available soil water in the spring for bloom, fruit set, and vegetative growth. The increased allowable soil water depletion in the summer and fall allows for more effective use of rainfall during the rainy season and sufficient water for fruit expansion.

\section{The Citrus Irrigation Scheduler}

To aid citrus growers in water management decision making, the Florida Automated Weather Network (FAWN) has developed a useful irrigation scheduling method:

http://fawn.ifas.ufl.edu/tools/irrigation/citrus/ scheduler/.

The computer-based support system was developed to improve water use efficiency for site-specific soil characteristics and local weather data. Grove in-row and between-row tree distances are used to estimate the canopy volume, which in turn is used to calculate root distribution. Irrigation system characteristics provided by the user are spray diameter, shape of wetting pattern, and flow rate. These factors are used to determine irrigation delivery rate and application time. Soil characteristics for a given site can be specified from a list of soil types. The current ET is automatically provided from a selected FAWN site near the grove and appropriate
$\mathrm{Kc}$ and allowable moisture depletion are used based on the current date. A schedule of days between irrigation and hours of irrigation duration are provided. Suggested irrigation application delays for rainfalls of up to one inch are also provided.

\section{Field Testing}

A field test of the Citrus Irrigation Scheduler was conducted in six groves for a period of three years. Weather stations were placed in the groves, irrigation schedules were provided to the grower cooperators, and soil moisture measurements were taken every half-hour. Evapotranspiration at these sites were compared with ET estimated at the closest FAWN site (Fig. 1). Soil moisture sensor data were also compared with values estimated from the model (Fig. 2). It was concluded that the web-based Citrus Irrigation Scheduler tool using the model described would provide the accuracy needed for grower irrigation decisions. Furthermore, it was concluded that FAWN stations provided reliable ET data for these grower irrigation schedules, thus growers would not be required to have and maintain their own weather stations.

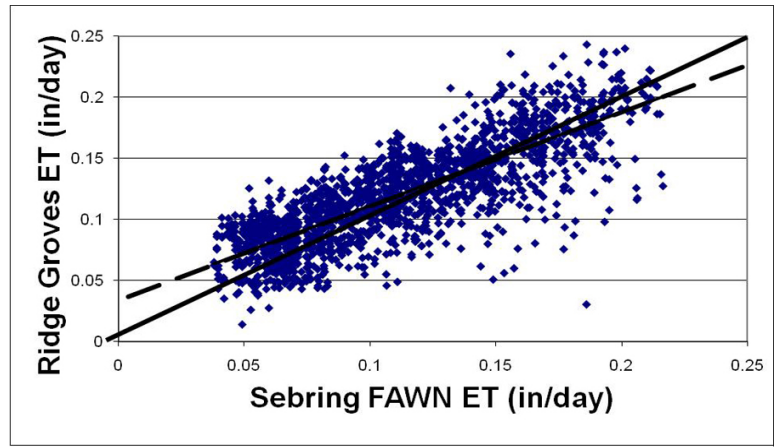

Figure 1. Comparison of calculated ET using data from the FAWN weather station site and ET calculated for the Ridge orchard sites. The solid line represents the 1:1 relationship line for the two locations. The dashed line and equation is the linear regression for the data.

\section{Conclusions}

We have discussed the importance of soil characteristics and rooting depth on irrigation scheduling. Understanding the root zone depth is key to determining the depth to which soil moisture must be managed by irrigation. Growers can then use generic tables, soil water balance, or soil water sensors to determine when the next irrigation should 


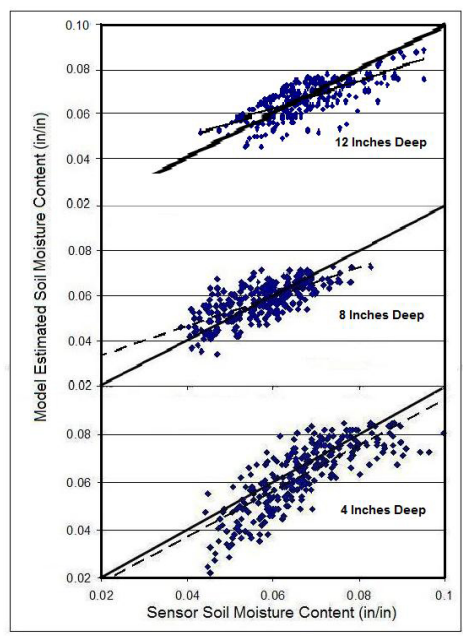

Figure 2. Comparison of model estimated and measured soil water content values at the 4, 8 and 12 inch soil depth. The solid line is the $1: 1$ relationship line indicating soil moisture sensor data is equal to the model estimated soil moisture content. The dashed line and equation is the linear regression of soil moisture sensor data and the estimated soil moisture and are nearly the same as the $1: 1$ relationship line indicating agreement among the sensors and model estimates.

occur. However, the grower needs to further understand that these irrigation schedules vary by time of year due to irrigation demand (ET) and allowable depletions. The use of a computer tool like the Citrus Irrigation Scheduler available at the FAWN Web site can simplify the calculations required for proper irrigation scheduling. With proper irrigation scheduling, sufficient water is provided for tree growth, fruit development, and yield. It can also protect the environment through reduced leaching of fertilizer nutrients, and improve the grower's bottom line by reducing costs of both water and fertilizer. 